\title{
dspace.vutbr.cz
}

\section{Voltage Differencing Current Conveyor Differential Input Transconductance Amplifier: Novel Active Element and Its Resistorless Filtering Application}

ŠOTNER, R.; JEŘÁBEK, J.; LANGHAMMER, L.; PETRŽELA, J.; JAIKLA, W.; TUNTRAKOOL, S.

Proceedings of the 2019 11th International Congress on Ultra Modern Telecommunications and Control Systems and Workshops (ICUMT), pp. 1-5

elSBN: 978-1-7281-5763-4

ISSN: 2157-023X

DOI: https://doi.org/10.1109/ICUMT48472.2019.8970754

Accepted manuscript

(C2019 IEEE. Personal use of this material is permitted. Permission from IEEE must be obtained for all other uses, in any current or future media, including reprinting/republishing this material for advertising or promotional purposes, creating new collective works, for resale or redistribution to servers or lists, or reuse of any copyrighted component of this work in other works. ŠOTNER, R.; JEŘÁBEK, J.; LANGHAMMER, L.; PETRŽELA, J.; JAIKLA, W.; TUNTRAKOOL, S. "Voltage Differencing Current Conveyor Differential Input Transconductance Amplifier: Novel Active Element and Its Resistorless Filtering Application", 2019 11th International Congress on Ultra Modern Telecommunications and Control Systems and Workshops (ICUMT), 2019.

DOI: 10.1109/ICUMT48472.2019.8970754. Final version is available at https://ieeexplore.ieee.org/document/8970754 


\section{Voltage Differencing Current Conveyor Differential Input Transconductance Amplifier: Novel Active Element and Its Resistorless Filtering Application}

\author{
Roman Sotner, Jan Jerabek, Lukas Langhammer, Jiri \\ Petrzela \\ SIX Research Center \\ Brno University of Technology \\ Brno, Czech Republic \\ sotner@feec.vutbr.cz
}

\author{
Winai Jaikla, Sunti Tuntrakool \\ Department of Engineering Education \\ Faculty of Industrial Education and Technology \\ King Mongkut's Institute of Technology Ladkrabang \\ Bangkok, Thailand
}

\begin{abstract}
This paper introduces novel modification of active element based on current conveyor transconductance amplifier core abbreviated as current controlled voltage differencing current conveyor differential input transconductance amplifier (CC-VDCCDITA). The active element is implemented by recently developed and manufactured IC modular device based on I3T25 $0.35 \mu \mathrm{m}$ ON Semiconductor CMOS process. Active element uses three internal active cells of this IC device for construction of the CC-VDCCDITA. An application example of proposed element in simple special resistor-less electronically adjustable biquadratic filter is shown. Brief comparison with state-of-the-art solutions indicates beneficial features of proposed solution. Simulation results in Cadence IC tool accompany precise laboratory experimental measurements with real prototype.
\end{abstract}

Keywords-active element; biquad filter; current conveyor transconductance amplifier; electronic control; modular approach

\section{INTRODUCTION}

The development of modern active devices reached significant attention in recent years. Many interesting concepts were introduced in literature [1], [2]. Common trend in this type of development supposes interconnection of modular blocks representing active sub-circuit (multiterminal active device) of specific type (current conveyor, operational transconductance amplifier, operational amplifier, voltage buffers, etc.). These sub-circuits (the suitable designation of sub-circuit is cells in IC terminology) provide electronically controllable parameters in many cases in order to achieve multiparametric adjustability of the device. Unfortunately, majority of these modern approaches is based on hypothetical concepts only (the device has never been practically designed ever fabricated) supported by simulation results with some uncomplete and basic technological models of active circuitries providing results that are not realistic (omitted influences of bonding, PCB, wires, loading capacities, etc.). Typical solutions were collected and described for example in [2].

This work introduces real experimental results of circuitry with fabricated CMOS device tested in intended application,

Research described in this paper was financed by Czech Ministry of Education in frame of National Sustainability Program under grant LO1401. Research described in the paper was supported by Czech Science Foundation project under No. 19-22248S. For the research, infrastructure of the SIX Center was used. not only simulation results with doubtful/inaccurate models. The active device belongs to family of so-called current conveyor transconductance amplifier (CCTA) firstly developed by Prokop et al. [3], [4] as non-adjustable devices connecting current conveyor (CCII) [1], [2] and operational transconductance amplifier (OTA) [1], [2] elements together. It brings many advantageous features for circuit synthesis [5], [6]. Several modifications (in the view of number of terminals and electronically adjustable features - significant degree of freedom) has been reported in recent years [5]-[11]. These generations of modifications include implementation of controlled current gain [7], non-adjustable additional voltage input operations [8], [9] and non-adjustable additional current input operations [10]. Nevertheless, to the best of authors' knowledge, improvements (adjustable additional voltage input operations) of CCTA defined in this paper, have not been reported in literature.

This paper includes definition of active device (Section II), application example (special biquad filter) shown in Section III, and comparison of experimental (measured) laboratory results with Cadence IC tool simulations shown in Section IV. Section $\mathrm{V}$ brings short comparison of features of presented biquad filter with similar concepts known from literature and Section VII concludes this paper.

\section{ACTIVE DEVICE PRoposal}

Modular approach of the active device building [3], [4] has been used also in our case. We developed complex IC designed in $0.35 \mu \mathrm{m}$ ON Semiconductor I3T25 CMOS process where several building cells are available [11]. These cells include controlled current conveyor of second generation (CCCII), voltage multipliers based on bipolar and unipolar multiplying core (MLTs), voltage-mode differential difference buffer (VDDB) and current amplifier. The full analysis and parameters of used cells can be found in [11]. Three of these cells (two multipliers and one CCCII) can be interconnected and implemented as newly defined active device shown in Fig. 1 and called as current controlled voltage differencing current conveyor differential input transconductance amplifier 
(CC-VDCCDITA). The device can be described by the following small-signal interterminal relations (inner terminals of cells and outer terminals of CC-VDCCDITA are distinguished by asterisk): $\quad I_{\mathrm{Za}^{*}}= \pm\left(V_{\mathrm{p}^{*}}-V_{\mathrm{n}^{*}}\right) \cdot g_{\mathrm{m} 1}$, $V_{\mathrm{X}^{*}}=V_{\mathrm{Za}^{*}}+R_{\mathrm{X}} I_{\mathrm{X}^{*}}, \quad I_{\mathrm{Zb}^{*}}=I_{\mathrm{X}^{*}}, \quad I_{\mathrm{O}^{*}}= \pm\left(V_{\mathrm{Zb}^{*}}-V_{\mathrm{v}^{*}}\right) \cdot g_{\mathrm{m} 2}$, $V_{\mathrm{p}^{*}}=V_{\mathrm{n}^{*}}=0$. The input resistance of the $\mathrm{X}$ terminal (CCCII) can be electronically controlled by DC current $I_{\text {set_RX }}$ as: $R_{\mathrm{X}} \cong 3.5 \cdot I_{\text {set_RX }}{ }^{-0.5}$. The transconductances of MLT-based operational transconductance amplifiers $\left(g_{\mathrm{m}} \mathrm{s}\right)$ are defined as $g_{\mathrm{m} 1} \cong 1.3 \cdot 10^{-3} \cdot V_{\text {set_gm } 1}, g_{\mathrm{m} 2} \cong 4.9 \cdot 10^{-3} \cdot V_{\text {set_gm2 }}$. The first value is valid for CMOS version, second for BJT version of MLT, see [11] for details. OTA is quite standard active element, however, in our case, the polarity of $g_{\mathrm{m}}$ can be easily changed by the polarity of $V_{\text {set_gm1,2. It is significant benefit for specific }}$ applications. This is also documented in Fig. 1 by bidirectional arrow of the $\mathrm{MLT}_{1,2}$ outputs.

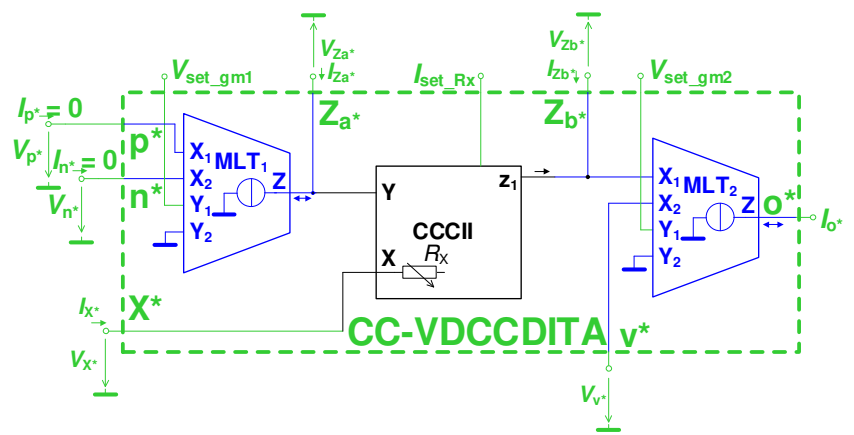

Fig. 1. Interconnection of internal cells in order to obtain CC-VDCCDITA active element.

\section{TransadmitTANCE BIQUAD FILTER Allowing VARIABLE PASS-BAND GAIN WHEN TUNED}

The biquadratic filter operating in so-called transadmittance mode is defined by $T(\mathrm{~s})=I_{\text {out }}(\mathrm{s}) / V_{\text {inp }}(\mathrm{s})$. Figure 2 shows two designed filtering topologies. In both cases, it consists of single CC-VDCCDITA element and two grounded capacitors. Transfer function for low-pass (LP) filter (Fig. 2a) is:

$$
T_{L P}(s)=\frac{I_{\text {out }}}{V_{\text {inp }}}=\frac{\frac{g_{m 1} g_{m 2}}{C_{1} C_{2} R_{X}}}{s^{2}+\frac{g_{m 2}}{C_{2}} s+\frac{g_{m 1}}{C_{1} C_{2} R_{X}}},
$$

Transfer response in case of band-pass (BP) filter (Fig. 2b) is:

$$
T_{B P}(s)=\frac{I_{\text {out }}}{V_{\text {inp }}}=\frac{\frac{g_{m 1}}{C_{1} R_{X}} s}{s^{2}+\frac{g_{m 2}}{C_{2}} s+\frac{g_{m 1}}{C_{1} C_{2} R_{X}}} .
$$

Pole frequency $\left(\omega_{\mathrm{p}}\right)$, quality factor $(Q)$ and bandwidth $(B W)$ of both the filters are as follows:

$$
\omega_{p}=\sqrt{\frac{g_{m 1}}{C_{1} C_{2} R_{X}}} \cong \sqrt{\frac{4.8 \cdot 10^{-3} V_{s e t_{-} g m 1}}{C_{1} C_{2} \cdot 3.5 \cdot\left(I_{s e t_{-} R X}\right)^{-0.5}}},
$$

$$
\begin{aligned}
& Q=\frac{1}{g_{m 2}} \sqrt{\frac{g_{m 1}}{R_{X}} \frac{C_{2}}{C_{1}}} \cong \\
& \cong \frac{1}{1.3 \cdot 10^{-3} V_{\text {set_gm2 }}} \sqrt{\frac{4.8 \cdot 10^{-3} V_{\text {set_gm1 }}}{3.5 \cdot\left(I_{\text {set_ } R X}\right)^{-0.5}} \frac{C_{2}}{C_{1}}}, \\
& B W=\frac{g_{m 2}}{C_{2}} \cong \frac{1.3 \cdot 10^{-3} V_{\text {set_gm2 }}}{C_{2}} .
\end{aligned}
$$

Note that $Q$ can be controlled by $g_{\mathrm{m} 2}$ without disturbing $\omega_{\mathrm{p}}$. The influence of $g_{\mathrm{m} 1}$ and $R_{\mathrm{X}}$ on pass-band gain of BP can be turned into benefit when this behavior is welcomed (some adaptive reacting circuits [12] for equalizing of the output response reacting on variable amplitude of input spectral components [12], [13]). The pass-band gain of BP is defined as:

$$
\begin{aligned}
& T_{0(\max )}\left(\omega_{p}\right)=\frac{g_{m 1}}{g_{m 2}} \cdot \frac{1}{R_{X}} \cong \\
& \cong \frac{4.8 \cdot 10^{-3} V_{s e t_{-} g m 1}}{1.3 \cdot 10^{-3} V_{\text {set_gm } 2}} \cdot \frac{1}{3.5 \cdot\left(I_{\text {set_ }_{-} X}\right)^{-0.5}}
\end{aligned} .
$$

The suitable parameters for tuning of the center frequency $f_{\mathrm{p}}$ and pass-band gain $\left(T_{0(\max )}\right)$ at center frequency are $g_{\mathrm{m} 1}$ and $R_{\mathrm{X}}$ simultaneously. All parameters can be adjusted electronically by DC bias current and DC voltages. The pass-band gain of the LP filter (1) can be found as: $T_{0}(\omega \rightarrow 0)=g_{\mathrm{m} 2} \cong 1.3 \cdot 10^{-3} \cdot V_{\text {set_gm2 }}$.

Some signals have complicated behavior in time and frequency response. So-called adaptive filtering circuits are defined for these purposes [12]. However very complex control systems including peak detection, adjustable amplifiers, etc. and their precise setting are sometimes required [13]. Is some cases it may be helpful when their cut-off or center frequency is tuned and pass band gain varies in dependence on certain trend (dependence of gain on driving force). This case can be interesting at band-pass response when amplitude of tuned input signal increases with frequency and band-pass filter has to follow these changes and compensate these effects (in order to obtain output response completely flat over several frequency bands but still filtered and with certain bandwidth).

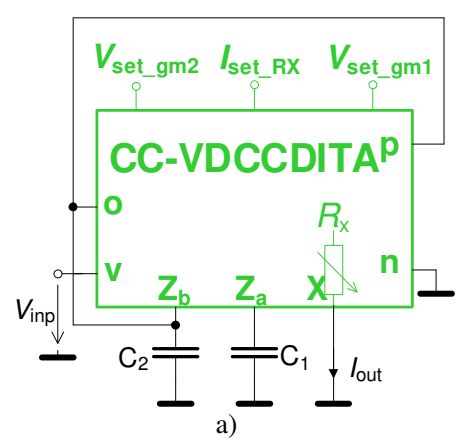




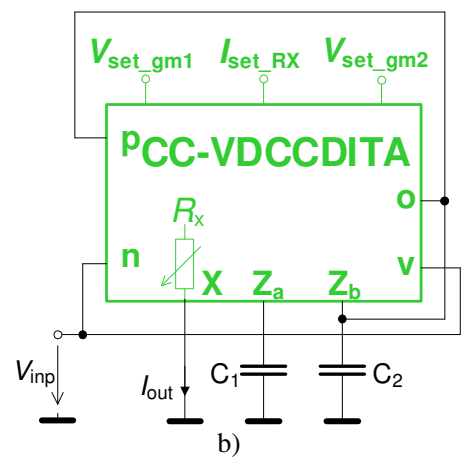

Fig. 2. Controllable biquadratic trans-admittance mode filter employing CCVDCCDITA in configuration providing: a) LP response, b) BP response.

\section{EXPERIMENTAL RESULTS}

Design parameters of the filters are as follows: $f_{\mathrm{p}}=10 \mathrm{kHz}$, $Q_{\mathrm{p}}=1 \quad$ considering $\quad C_{1}=C_{2}=C=10 \mathrm{nF}, \quad R_{\mathrm{X}}=1 \mathrm{k} \Omega$ $\left(I_{\text {set_Rx }} \cong 20 \mu \mathrm{A}\right)$. Then, resulting parameters for initial setting of the filters are: $g_{\mathrm{m} 1}=395 \mu \mathrm{S} \quad\left(V_{\text {set_gm1 }}=0.08 \mathrm{~V}\right)$ and $g_{\mathrm{m} 2}=630 \mu \mathrm{S}\left(V_{\text {set_gm2 }}=0.48 \mathrm{~V}\right)$. Note that dependency of $g_{\mathrm{m} 2}$ (CMOS MLT) on control voltage $\left(V_{\text {set_gm2 }}\right)$ is not the same as in case of $g_{\mathrm{m} 1}$ (BJT MLT) [11]. Figure 3 shows simulated and measured frequency responses of the filter in BP configuration. Decreasing of the value of $g_{\mathrm{m} 2}(5)$ leads to increased value of $Q_{\mathrm{p}}$ as documented also in Fig. 3. Important parameters are shown directly in figures. Figure 4 brings results of the LP response for two different values of $Q_{\mathrm{p}}$.

The adjustment of pass-band gain of BP response together with $f_{\mathrm{p}}$ tuning was also tested by $R_{\mathrm{X}}$ and $g_{\mathrm{m} 1}$ variation. Variation of $g_{\mathrm{m} 1}$ results in pole frequency and quality factor change as shown in Fig. 5 for $g_{\mathrm{m} 1}=253 \mu \mathrm{S}$ and $2467 \mu \mathrm{S}$ $\left(V_{\text {set_gm } 1}=0.05 \mathrm{~V}\right.$ and $0.5 \mathrm{~V}$ ). This adjustment allows theoretical change of pass-band gain from -68 up to $-48 \mathrm{~dB}$ $\left(\Delta T_{0(\max )}=20 \mathrm{~dB}\right)$ and pole frequency tuning from $7.8 \mathrm{kHz}$ up to $24.6 \mathrm{kHz}$. Real experiments yield $T_{0(\max )}$ change from -69 up to $-49 \mathrm{~dB}$ and $f_{\mathrm{p}}$ between $8.4 \mathrm{kHz}$ and $27 \mathrm{kHz}$.

The adjustment of $R_{\mathrm{X}}$ (by $I_{\text {set_RX) offers reduced range of }}$ tuning of center frequency $f_{\mathrm{p}}$ and $T_{0(\max )}$ than in case of control by $g_{\mathrm{m} 1}\left(V_{\text {set_gm1 }}\right)$. The theoretically expected $T_{0(\max )}$ tuning range is from -69 up to $-59 \mathrm{~dB}\left(\Delta T_{0(\max )}=10 \mathrm{~dB}\right)$. Experimentally achieved value is $\Delta T_{0(\max )}=8 \mathrm{~dB}, T_{0(\max )}$ can be varied from $72 \mathrm{~dB}$ up to $-64 \mathrm{~dB}$. The impact is significantly lower due to the character of $R_{\mathrm{X}}$ dependence on $I_{\text {set_RX. The similar }}$ limitations are valid also for $f_{\mathrm{p}} \quad(5.9 \mathrm{kHz} \rightarrow 14.1 \mathrm{kHz}$ theoretically; $9.5 \mathrm{kHz} \rightarrow 16.9 \mathrm{kHz}$ experimentally). Results are illustrated in Fig. 6. However, it can be useful when small-step of change of $f_{\mathrm{p}}$ and consequently also $T_{0(\max )}$ is useful for application. The disadvantage of this approach $\left(R_{\mathrm{X}}\right)$ consists in the accuracy of $R_{\mathrm{X}}$ dependence on $I_{\text {set_RX }}$ (there are significant fabrication tolerances that cannot be neglected).

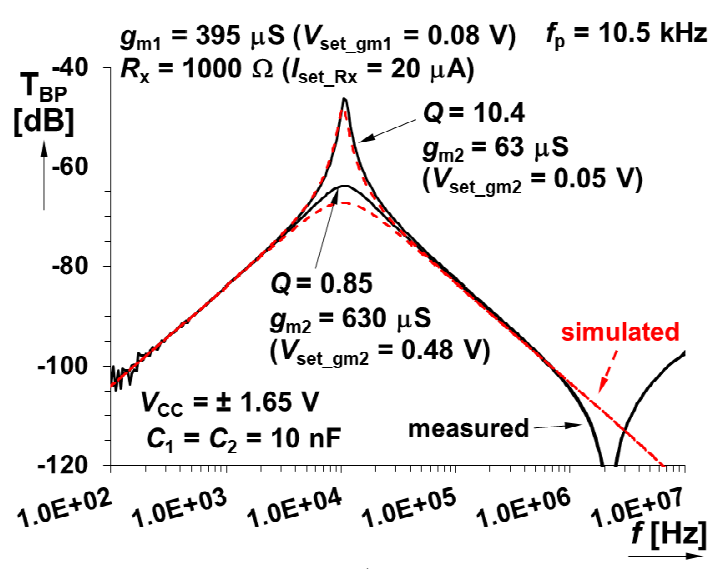

a)

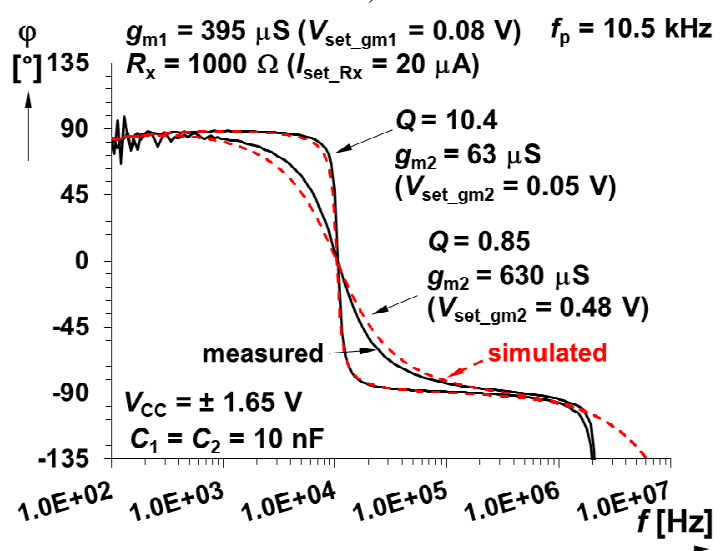

b)

Fig. 3. Comparison of measured and simulated frequency responses of proposed trans-admittance filter in BP configuration: a) magnitude responses, b) phase responses.

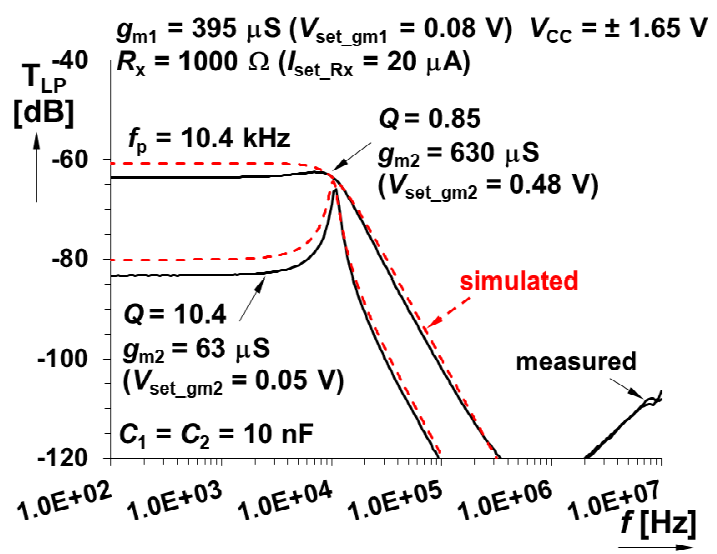

a) 


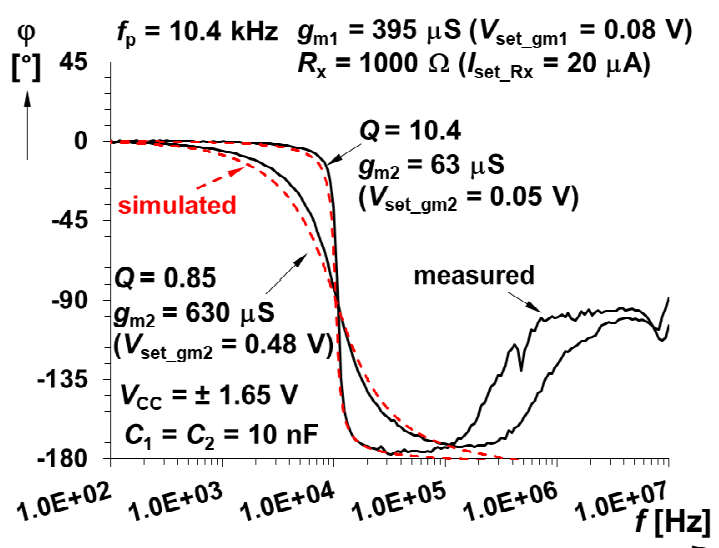

b)

Fig. 4. Comparison of measured and simulated frequency responses of proposed trans-admittance filter in LP configuration: a) magnitude responses, b) phase responses.

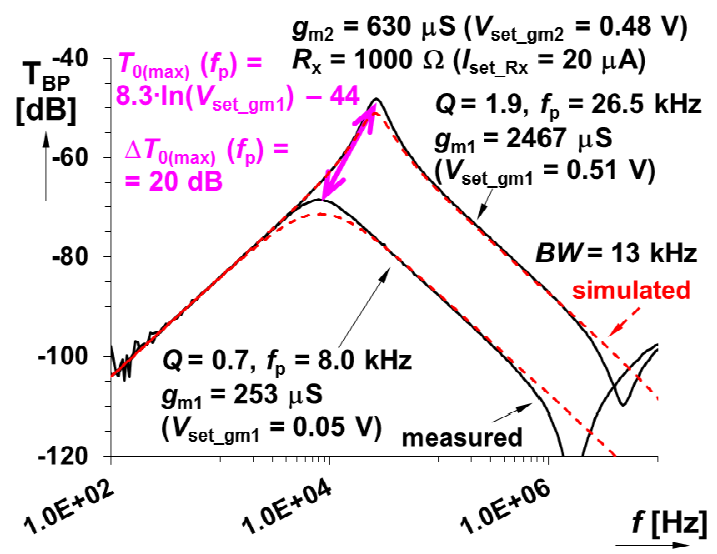

Fig. 5. Exemplary magnitude responses of the trans-admittance mode filter for: $g_{\mathrm{m} 1}\left(V_{\text {set_gm1 }}\right)$ variation (simulation vs. measurement).

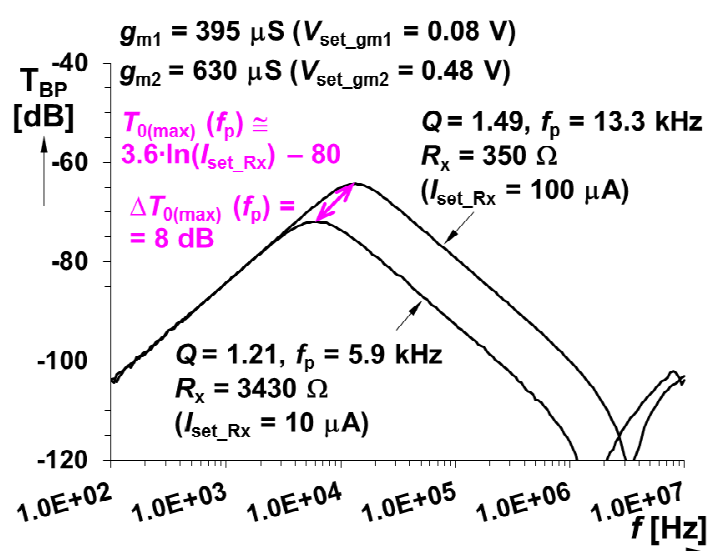

Fig. 6. Exemplary magnitude responses of the trans-admittance mode filter for: $R_{\mathrm{X}}\left(I_{\text {set_RX }}\right)$ variation.

\section{COMParison of Proposed Filters With The State OF THE ART}

Both proposed solutions of the trans-admittance filter (Fig. 2) has these advantages available simultaneously: a) all passive elements grounded, b) adjusting of quality factor independent on pole frequency, c) simple change between BP and LP response (reconnection of single terminal), d) high input impedance, e) relatively low (in dependence on $R_{\mathrm{X}}$ ) output impedance. Table I brings comparison of relevant recently developed trans-admittance-mode filters. However, their complexity is not similar to proposed circuit in Fig. 2. These solutions target to full universality and, therefore, more than one active element is required in majority of them. Our solution offers lower multifunctionality (only LP and BP responses are available) but simple electronic controllability of quality factor is possible. It is not the case in many of recent and more complex solutions [14]-[21].

TABLE I. COMPARISON OF RELEVANT REPORTED SELECTED TRANSADMITTANCE-MODE BIQUADS.

\begin{tabular}{|c|c|c|c|c|c|c|}
\hline 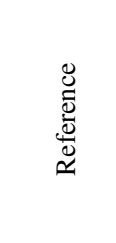 & 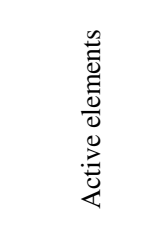 & 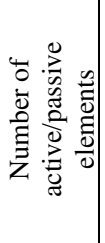 & 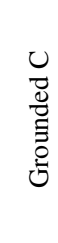 & 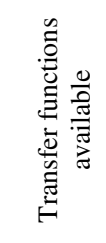 & 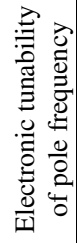 & 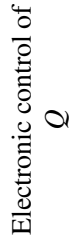 \\
\hline$[14]$ & CCII & $3 / 5$ & No & $\begin{array}{l}\text { HP, BP, } \\
\text { LP }\end{array}$ & No & No \\
\hline [15] & FTFN & $3 / 5$ & No & $\begin{array}{l}\mathrm{HP}, \mathrm{BP}, \\
\text { LP }\end{array}$ & No & No \\
\hline$[16]$ & CDTA & $2 / 4$ & Yes & $\begin{array}{c}\mathrm{HP}, \mathrm{BP}, \\
\mathrm{LP}, \mathrm{BR}, \\
\text { AP }\end{array}$ & N/A & N/A \\
\hline [17] & CDTA & $2 / 4$ & Yes & $\begin{array}{c}\mathrm{HP}, \mathrm{BP}, \\
\mathrm{LP}, \mathrm{BR}, \\
\text { AP }\end{array}$ & N/A & N/A \\
\hline [18] & VDTA & $2 / 2$ & Yes & $\begin{array}{l}\text { HP, BP, } \\
\text { LP, BR, } \\
\text { AP }\end{array}$ & N/A & N/A \\
\hline [19] & MO-CCCII & $3 / 2$ & Yes & $\begin{array}{c}\mathrm{HP}, \mathrm{BP}, \\
\mathrm{LP}, \mathrm{BR}, \\
\text { AP }\end{array}$ & Yes & N/A \\
\hline [20] & MO-CCCII & $3 / 2$ & Yes & $\begin{array}{l}\text { HP, BP, } \\
\text { LP, BR, } \\
\text { AP }\end{array}$ & Yes & N/A \\
\hline [21] & MOCDTA & $2 / 4$ & Yes & $\begin{array}{l}\text { HP, BP, } \\
\text { LP, BR }\end{array}$ & N/A & N/A \\
\hline proposed & $\begin{array}{c}\mathrm{CC}- \\
\text { VDCCDITA }\end{array}$ & $1 / 2$ & Yes & $\mathrm{LP}, \mathrm{BP}$ & Yes & Yes \\
\hline
\end{tabular}

Notes:

CCII - current conveyor of second generation; CC-VDCCDITA - current controlled voltage differencing current conveyor differential input transconductance amplifier; CDTA - current differencing transconductance amplifier; FTFN - four terminal floating nullor; MO-CCCII - multi-output current controllable CCII; MO-CDTA - multi-output CDTA; OFCC operating floating current conveyor; VDTA - voltage differencing transconductance amplifier; N/A - not available, not solved or not tested; HP - high-pass filter, BP - band-pass filter, LP - low-pass filter, BR - band-reject filter, AP - all-pass filter.

\section{CONCLUSION}

Application example of active element presented in this contribution indicates useful features of modular approach and simplification of overall circuitry (all parts of CC-VDCCDITA are integrated on single chip package [11]). Proposed application was tested in bands from hundreds of $\mathrm{Hz}$ up to ten $\mathrm{MHz}$ because this operational band fits performance of developed modular device. Experiments confirmed adjustable 
features of presented filtering topology (quality factor and center frequency control). The effect of adjustability in case of BP response (arranged by $R_{\mathrm{X}}$ and $g_{\mathrm{m} 2}$ parameters) suitable for adaptive applications brings two ways of pass-band gain and center frequency tuning simultaneously. The $g_{\mathrm{m} 1}$ adjustment provides more than two-times wider change of $f_{\mathrm{p}}$ $(8.4 \rightarrow 27 \mathrm{kHz})$ and $T_{0(\max )}(-69 \rightarrow-49 \mathrm{~dB})$ than $R_{\mathrm{X}}$ driving. But both methods can be useful when different trend of influence on frequency response is necessary. The future design expects modification of topology allowing reconnection-less purposes [13] and more transfer functions (better multifunctionality) than presented examples.

\section{REFERENCES}

[1] D. Biolek, R. Senani, V. Biolkova, Z. Kolka, "Active elements for analog signal processing: Classification, Review and New Proposals," Radioengineering, vol. 17, no. 4, pp. 15-32, 2008.

[2] R. Senani, D. R. Bhaskar, and A. K. Singh, Current Conveyors: Variants, Applications and Hardware Implementations. Switzerland: Springer International Publishing, 2015.

[3] R. Prokop, V. Musil, "Modular approach to design of modern circuit blocks for current signal processing and new device CCTA," In Proc. of the 7th Int. Conf. on Signal and Image Processing, 2005, pp. 494-499.

[4] R. Prokop, V. Musil, "New modular current devices for true current mode signal processing," Electronics, vol. 16, pp. 36-42, Sept. 2007.

[5] M. Siripruchyanun, W. Jaikla, "Current controlled current conveyor transconductance amplifier (CCCCTA): a building block for analog signal processing," In Proc. of the International Symposium on Communications and Information Technologies (ISCIT), 2007, 209212.

[6] M. Siripruchyanun, P. Silapan, W. Jaikla, "Realization of CMOS Current Controlled Current Conveyor Transconductance Amplifier (CCCCTA) and Its Applications," Journal of Active and Passive Electronic Devices, vol. 4, pp. 35-53, 2009.

[7] R. Sotner, J. Jerabek, R. Prokop, K. Vrba, "Current Gain Controlled CCTA and its Application in Quadrature Oscillator and Direct Frequency Modulator," Radioenginnering, vol. 20, no. 1, pp. 317-326 2011.

[8] W. Tangsrirat, O. Channumsin, "High-Input Impedance Voltage-Mode Multifunction Filter Using a Single DDCCTA and Grounded Passive Elements," Radioengineering, vol. 20, no. 4, pp. 905-910, 2011.
[9] N. Pandey, P. Kumar, "Realization of Resistorless Wave Active Filter using Differential Voltage Current Controlled Conveyor Transconductance Amplifier," Radioengineering, vol. 20, no. 4, pp. 911-916, 2011.

[10] A. Kumar, B. Chaturvedi, "Novel CMOS Dual-X Current Conveyor Transconductance Amplifier Realization with Current-Mode Multifunction Filter and Quadrature Oscillator," Circuits, Systems and Signal Processing, vol. 37, no. 6, pp. 2250-2277, 2018.

[11] R. Sotner, J. Jerabek, L. Polak, R. Prokop, V. Kledrowetz, "Integrated Building Cells for Simple Modular Design of Electronic Circuits with Reduced External Complexity: Performances, Active Element Assembling and Application Example," Electronics, vol. 8, no. 5 (568), pp. 1-26, 2019.

[12] A. H. Sayed, Adaptive filters, John Wiley and Sons Ltd., 2008.

[13] R. Sotner, J. Jerabek, J. Petrzela, L. Langhammer, O. Domansky, W. Jaikla, T. Dostal, "Reconnection-less Reconfigurable Filter and its Application into Adaptive Circuit," In Proc. of the 41 $1^{\text {st }}$ International Conference on Telecommunications and Signal Processing (TSP), 2018, pp. 192-197.

[14] A. Toker, O. Cicekoglu, S. Ozcan, H. Kuntman, "High-outputimpedance transadmittance type continuous-time multifunction filter with minimum active elements," International Journal of Electronics, vol. 88, no. 10, p. 1085-1091, 2001.

[15] N. A. Shah, S. Z. Iqbal, B. Parveen, "SITO high output impedance transadmittance filter using FTFNs," Analog Integrated Circuits and Signal Processing, vol. 40, p. 87-89, 2004.

[16] N. A. Shah, M. Quadri, S. Z. Iqbal, "CDTA based universal transadmittance filter," Analog Integrated Circuits and Signal Processing, vol. 52, p. 65-69, 2007.

[17] F. Kacar, H. Kuntman, "A new cmos current differencing transconductance amplifier (CDTA) and its biquad filter application," In Proc. of Int. Conf. Eurocon, 2009, pp. 189-196.

[18] D. Prasad, M. Srivastava, D. R. Bhaskar, "Transadmittance Type Universal Current-Mode Biquad Filter Using VDTAs," International Scholarly Research Notices, vol. 2014, pp. 1-4, 2014.

[19] N. Pandey, S. K. Paul, "SIMO Transadmittance Mode Active-C Universal Filter," Circuits and Systems, vol. 1, no. 2, pp. 54-58, 2010.

[20] S. K. Paul, N. Pandey, A. Bhattacharyya, "Transadmittance Mode Universal Filter Based on MOCCCII," In Proc. of 4th Int. Conf on Computers and Devices for Communication (CODEC), 2009, pp. 1-4.

[21] P. Singh, M. Dehran, I. Singh, R. K. Singh, "Universal transadmittance filter using CMOS MOCDTA," In Proc. of. 11th Int. Conf on Wireless and Optical Communications Networks (WOCN), 2014, pp. 1-4. 